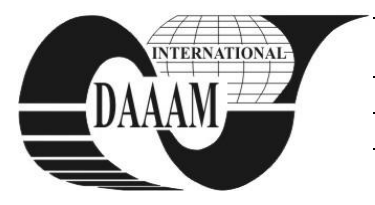

Annals of DAAAM for 2012 \& Proceedings of the 23rd International DAAAM Symposium, Volume 23, No.1, ISSN 2304-1382 ISBN 978-3-901509-91-9, CDROM version, Ed. B. Katalinic, Published by DAAAM International, Vienna, Austria, EU, 2012 Make Harmony between Technology and Nature, and Your Mind will Fly Free as a Bird

\title{
EXPERIMENTAL ANALYSIS OF THE LASER-SINTERING PROCESS FROM AN ENERGETIC POINT OF VIEW
}

\author{
REINHARDT, Thomas] \& WITT, G[erd]
}

\begin{abstract}
Additive manufacturing processes such as lasersintering are able to produce end-use parts of nearly any complexity. Furthermore the additive manufacturing offers opportunities for a minimum-waste production and sustainable manufacturing. Hence the laser-sintering process has the potential to be an environmental alternative to conventional processes, but only a few papers deal with time studies, energy consumption as well as powder consumption of the additive manufacturing process. This paper presents first results of analyses of the laser-sintering process from the energetic point of view. First all modes of the process are itemized within a time study. Subsequently attention is paid to the electrical energy consumption, in particular all major consumers are investigated. Finally improvement suggestions for the lasersintering process based on the results are presented.

Keywords: additive manufacturing, rapid prototyping, lasersintering $(L S)$, environmental management, energy consumption
\end{abstract}

\section{INTRODUCTION}

Additive manufacturing refers to a group of technologies used for manufacture prototypes (Rapid Prototyping), tooling (Rapid Tooling) and production parts (Rapid Manufacturing). In contrast to conventional manufacturing processes, models are built up layer by layer. So during the last years additive manufacturing is successfully used as an effective tool for the rapid development of products of nearly any complexity $[1,2]$.

According to a survey of the Wohler association [1] companies are using additive manufacturing processes more and more for functional models and direct part production. Especially in the field of individual and small-scale production additive manufacturing have become increasingly important. They complement the conventional manufacturing processes and create new possibilities in subsequent processes. For these reasons the market has expanded rapidly over the last ten years, which means more units were both sold as well as producing more parts with additive manufacturing [1].

The use of additive manufacturing is established in a variety of properties. Due to the additive process which builds up the physical part layer by layer, geometries of any complexity like undercuts and internal features can be built, because the whole geometry of the part is not of importance in the current layer. In addition they have an minimum waste of material compared to the conventional methods. Furthermore no tooling is necessary, so nether cooling lubricants nor any large storage areas for spare tools are required. Other ecological advantages can be found in the reduction of supply or transportation chain. Because of that additive manufacturing is often prized for being much cleaner than conventional processes [3].

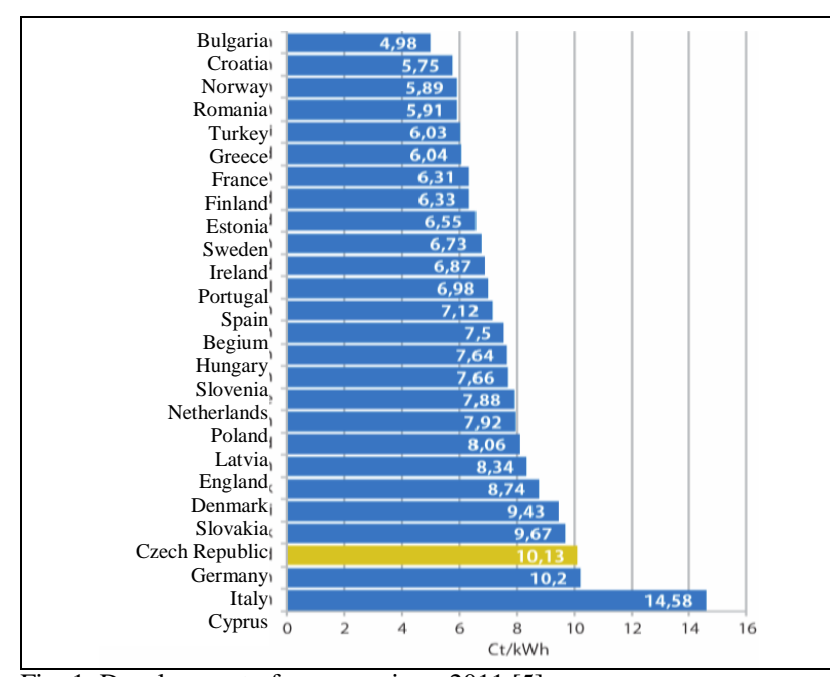

Fig. 1. Development of energy prices, 2011 [5]

Despite the additive manufacturing continues to expand and new systems are developed, new applications found and more materials used, there have been too few observations about the energy consumption or any other environmental impacts of this technology. To improve the process performance the energy consumption has to be reduced, the waste has to be minimized and resources has to be used efficiently [4]. Hence reducing the energy consumption is an essential consideration in sustainable manufacturing, especially in regard to the rising electricity prices in recent years. In the European comparison, Germany's electricity prices take a top position, see Fig. 1.

\section{ADDITIVE MANUFACTURING PROCESS CHAIN}

Additive manufacturing describes all manufacturing processes, which build up parts layer by layer. Since first appearance in 1987 [1] the additive manufacturing have become an integral part of the product development process.

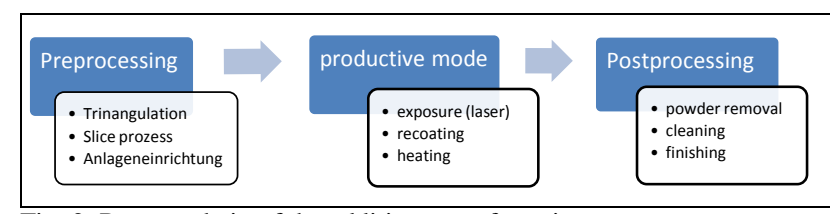

Fig. 2. Process chain of the additive manufacturing process 
As shown in Fig. 2 every additive manufacturing process is characterized by the preprocessing, the main building of the part and the post process.

For every additive manufacturing process a CAD data is the basis [6]. Nearly every AM machine accepts the STL file format, which describes the external closed surfaces of the original CAD model and is used for calculation of the slices [7]. With the slicing process the part is divided into layers and can be passed to the system. The layer thickness corresponds to the chosen height of material applied during the construction process. Depending on the AM process several finishing steps follow to guarantee the quality of the part, see Fig. 2.

In particular, the laser-sintering process has been proved along the beam melting process as a potential process for future rapid manufacturing. The principle of the process is shown in Fig. 3.

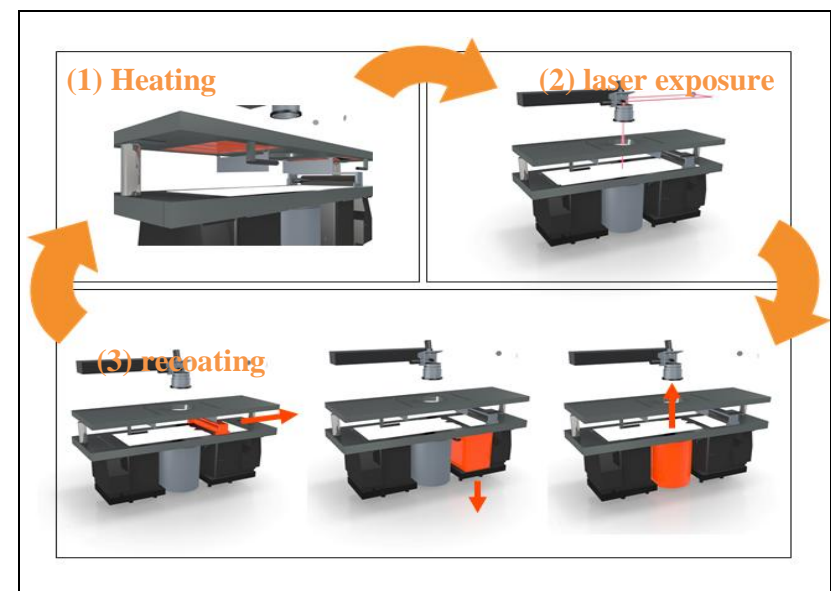

Fig. 3. Method description of laser-sintering

The default material for laser-sintering is a powdered plastic, typically with an average grain diameter from 20$50 \mu \mathrm{m}$. After a powder layer (normally $0.1 \mathrm{~mm}$ ) is laid on the building platform, a laser beam scans the powder bed tracing the layer geometry. Subsequently, the building platform is moved down equal to the chosen layer thickness and the feed container moves upward by a defined height. A roller puts a new layer homogenously on the already solidified layer. This process continues until the parts are completely produced. Afterwards the parts cool down, before it can be cleaned. To improve several properties, such as the surface of the part, different post-processing steps are necessary.

\section{PROTOCOL OF TESTS}

The studies were performed on a DTM 2000 machine from 3D Systems, using PA2200 from EOS. All studies were carried out with the same standard process parameters:

- Laser power (Fill): 5,5W

- Scan speed (Fill): $1257 \mathrm{~mm} / \mathrm{sec}$

- Hatch: 0,12 mm

- Layer thickness: 0,1 mm

- Laser power (Outline): $1,5 \mathrm{~W}$

- Scan speed (Outline): 279,40 $\mathrm{mm} / \mathrm{sec}$

In carrying out the investigations only the productive phase of the laser-sintering process were included. The length of time of the pre-processing as well as the postprocessing depends strongly on the machine user. So it is not possible to define consistent statements over the period. Because of that, preparing measures, such as the machine facility, the repairing, positioning and orientation of the components, as well as the slicing process and the parameter assignment were not examined. After the productive mode and the cooling of the powder cake, all components are extracted from the building cylinder. The components are freed from the powder in an separate unpacking station. In a further post-processing step, the remaining powder is removed with a subsequent blasting process. For this reason, the following investigations are restricted only to the productive mode of the laser-sintering machine.

The duration of the productive mode and the energy consumption depends mainly of the process load, e.g. the number of products, their complexity and volume as well as the final batch height. Therefore five different process situations were defined (Fig. 4). The test geometry is a cube with the dimensions $\mathrm{x}=20 \mathrm{~mm}, \mathrm{y}=20 \mathrm{~mm}$ und $\mathrm{z}=$ $20 \mathrm{~mm}$.

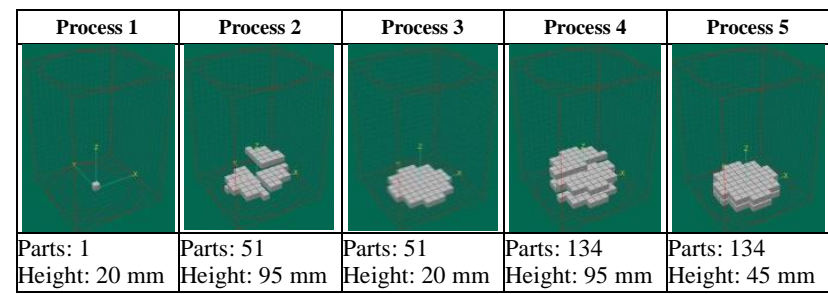
Fig. 4. Test runs

\section{TIME STUDIES}

Regardless of the number of parts which were build and the nesting efficiency several phases can be identified:

- Preheating

- Productive Phase

- Cooling Down

The duration of the preheating phase is inherited by the machine and amounts about 126 minutes. Here the powder bed is heated to a few degrees below the melting point. Thus the energy input, to solidify the powder with the laser, is held to a minimum. Hereby the product quality has to be ensured, because the distortion, which could occur due thermally inducted stresses, can be avoided. The duration of the productive phase is mainly determined by the total volume of the components and the final batch height. The productive phase of the fifth test build (with 134 test geometries) totals up about $80 \%$ of the total process time, see Fig. 5. In contrast the productive phase of the additive manufacturing of only one part, see test process 1 , takes about $27 \%$. The cooling down phase consists of two phases. In the first phase 50 layers were laid on the building platform to ensure a uniform heat emission. After the parts cooled down to room temperature in the second phase, the powder cake can be extracted. The cooling down phase lasts 2 hours (process 1) to $17 \mathrm{~h}$ (process 4 ). 


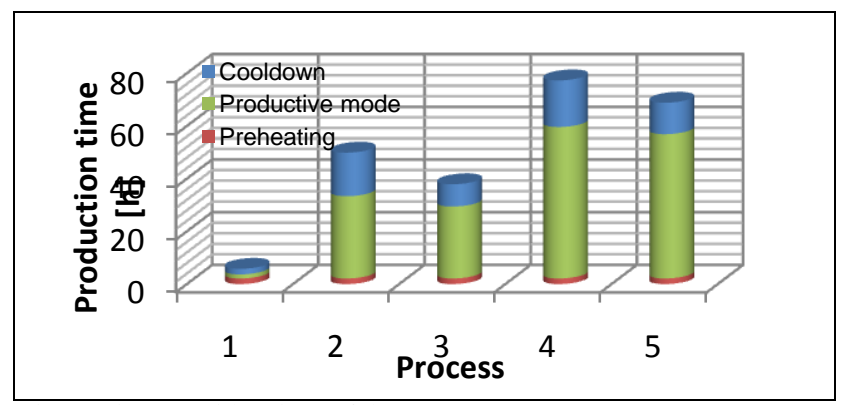

Fig. 5. Time considerations of the processes

Exemplary Fig. 6 shows the overtime comparison of the identified modes, based on the second test run. All in all 51 test geometries were built with a total production time of $50 \mathrm{~h}$ hours. The productive phase is responsible for about $62,63 \%$ of the total production time, and can be sub classified forward into three modes: the exposure of the laser $(50,40 \%)$, the recoating of new powder layer $(7,42 \%)$, and the following heating of the new powder layer $(4,77 \%)$.

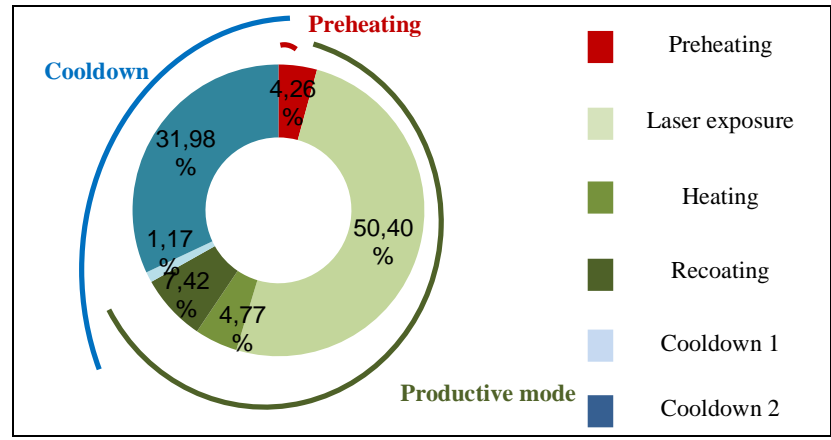

Fig. 6. Process 4

The results of the temporal investigations are summarized in Tab. 1. As expected, the total construction time depends mainly on the number of parts, their volume and dimensions, and therefore of the total batch height. The more layers which are built, the longer the process lasts.

\begin{tabular}{|c|c|c|c|c|c|}
\hline Process & 1 & 2 & 3 & 4 & 5 \\
\hline Number of parts & 1 & 51 & 51 & 134 & 134 \\
\hline Total time & $5,78 \mathrm{~h}$ & $49,88 \mathrm{~h}$ & $37,90 \mathrm{~h}$ & $77,32 \mathrm{~h}$ & $68,84 \mathrm{~h}$ \\
\hline$\rightarrow$ Preheating & $2,1 \mathrm{~h}$ & $2,1 \mathrm{~h}$ & $2,1 \mathrm{~h}$ & $2,1 \mathrm{~h}$ & $2,1 \mathrm{~h}$ \\
\hline$\rightarrow$ Production mode & $1,56 \mathrm{~h}$ & $31,24 \mathrm{~h}$ & $27,31 \mathrm{~h}$ & $57,51 \mathrm{~h}$ & $54,77 \mathrm{~h}$ \\
\hline$\longrightarrow$ Laser exposure & $14,27 \%$ & $80,39 \%$ & $94,19 \mathrm{~h}$ & $89,26 \%$ & $93,92 \mathrm{~h}$ \\
\hline$\longrightarrow$ Heating & $35,68 \%$ & $7,60 \%$ & $2,85 \%$ & $4,13 \%$ & $2,97 \%$ \\
\hline$\longrightarrow$ Recoating & $49,96 \%$ & $11,83 \%$ & $2,85 \%$ & $6,42 \%$ & $3,20 \%$ \\
\hline$\longrightarrow$ Cool down & $2,10 \mathrm{~h}$ & $16,52 \mathrm{~h}$ & $8,46 \mathrm{~h}$ & $17,69 \mathrm{~h}$ & $11,94 \mathrm{~h}$ \\
\hline$\longrightarrow$ Phase 1 & $27,75 \%$ & $3,53 \%$ & $6,89 \%$ & $3,30 \%$ & $4,88 \%$ \\
\hline$\longrightarrow$ Phase 2 & $72,25 \%$ & $96,47 \%$ & $93,11 \%$ & $96,70 \%$ & $95,12 \%$ \\
\hline production time / part & $5,78 \mathrm{~h}$ & $0,98 h$ & $0.74 h$ & $\mathbf{0 , 5 8 h}$ & $0,51 h$ \\
\hline productivity & $1,25 \frac{g}{h}$ & $9,45 \frac{g}{h}$ & $12.35 \frac{g}{h}$ & $12,06 \frac{g}{h}$ & $13,64 \frac{g}{h}$ \\
\hline
\end{tabular}

Tab. 1. Distribution
The effective construction time for each part can be reduced with the amount of parts built with one process. The single manufacturing of the geometry (process 1) lasts about $t_{1}=6$ hours. With a joint production of 134 test geometries the time for each part is reduced up to $t_{4}=$ 0,51 hours. Once the exact number and the volume of the parts are determined, the total production time can be reduced by optimizing the product nesting and orientation to minimize the batch height, compare process 1, 2 and 3 as well as process 1, 4 and 5 .

\section{ELECTRIC POWER STUDIES}

In the course of investigations with the DTM 2000 a number of components have been identified as a major customer and can be summarized into five main categories:

- Laser

oLaser unit

oLaser cooling

oScanner system

- Heating elements

oPlatform heating

oFrame heating

oProcess chamber heating

- Stepper motors

- Powder dosage chamber

- Building platform

- Recoating system

- Nitrogen circulation unit

- Periphery

All components are detected by a measuring system (Fig. 7) and analyzed with appropriate software.

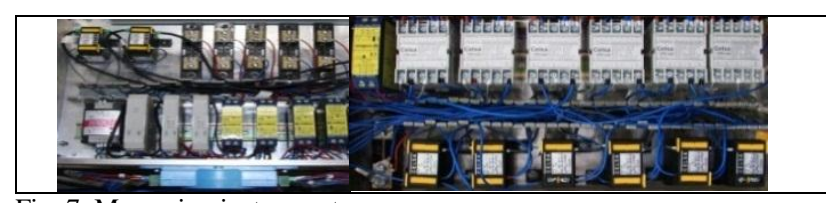

Fig. 7. Measuring instrument

As expected the energy consumption increases in dependence of the whole production time. The main influence of energy consumption has the productive mode. The consumption of preheating $(\sim 11 \mathrm{kWh})$ and cool down $(1,3 \mathrm{kWh})$ is constant. The average power level of preheating is between $4,73 \mathrm{~kW}-5,47 \mathrm{~kW}$, making it therefore the most energy intensive phase, because of the heating system which heats the process chamber to the desired temperature. The total energy consumption per $g$ decreases with the parts built up simultaneously in one process down to $0,187 \mathrm{kWh} / \mathrm{g}$, see Fig. 8 .

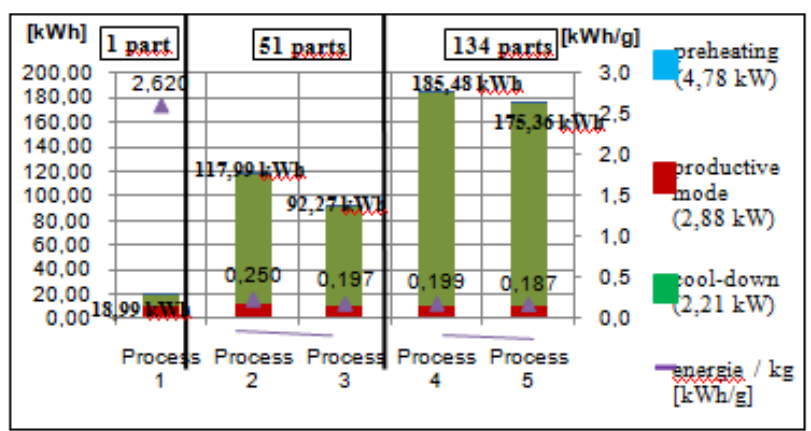

Fig. 8. Average Power Level of the third test run 
The average machine tool power levels during the entire process time are shown in Fig. 9. The laser and the cooling unit are identified as the major consumers $(1,23$ $\mathrm{kW}$ ) with $51,87 \%$ of the total machine tool power. Especially in the preheating phase, the consumption of the heating elements is extreme. Over the whole process the heating subunit is responsible for $35,00 \%$ of the machine power. To create a protective inert atmosphere, the process chamber is flooded with a continuous flow rate of $0,25 \mathrm{~m}^{3} / \mathrm{h}$ nitrogen. The stepper motors for the piston control and the roller unit consume about $9,87 \%$ $(0,23 \mathrm{~kW})$ of the total electrical power. The consumption of the nitrogen circulation unit $(0,79 \%)$ as well as the remaining components $(2,46 \%)$ are relatively low.

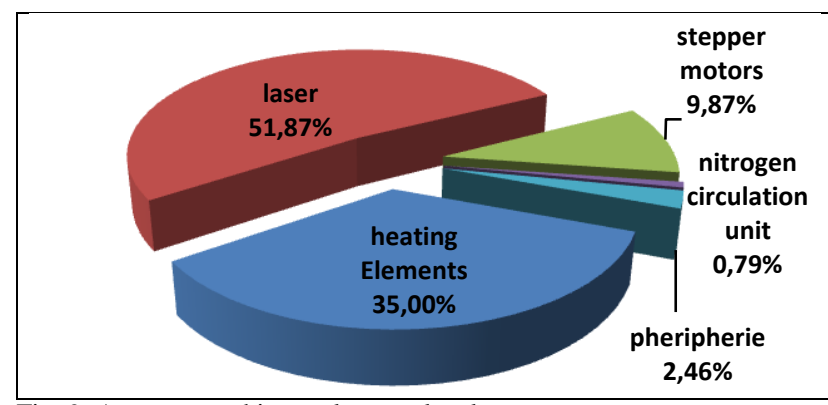

Fig. 9. Average machine tool power levels

\section{MATERIAL STUDIES}

The material consumption rises as a function of the process height. The waste material rates approximately $99 \%$ for building one test geometry (process 1) and falls with building 134 parts in one process and a total process height of $45 \mathrm{~mm}$ to $86 \%$, see Tab. 2. Most of the waste powder can be found in the overflow chambers, independent from the number of parts. About $60 \%$ of the remaining powder is recycled (30\% overflow and $30 \%$ building platform) and refreshed with $40 \%$ unused powder material. This refresh rate suggested within the manufactures recommendations about the refresh rates [12].

\begin{tabular}{|l|c|c|c|c|c|}
\hline & $\mathbf{1}$ & $\mathbf{2}$ & $\mathbf{3}$ & $\mathbf{4}$ & $\mathbf{5}$ \\
\hline Total weight & $5,49 \mathrm{~kg}$ & $9,62 \mathrm{~kg}$ & $6,10 \mathrm{~kg}$ & $9,55 \mathrm{~kg}$ & $6,69 \mathrm{~kg}$ \\
\hline \hline Parts & $0,13 \%$ & $4,90 \%$ & $7,67 \%$ & $9,77 \%$ & $14,03 \%$ \\
\hline Overflow & $39,9 \%$ & $55,66 \%$ & $41,15 \%$ & $55,16 \%$ & $45,39 \%$ \\
\hline Building platform & $59,89 \%$ & $39,45 \%$ & $51,18 \%$ & $35,07 \%$ & $40,58 \%$ \\
\hline
\end{tabular}

Tab. 2. Powder rates

\section{FUTURE RESEARCH POSSIBILITIES}

The manufacturing time is the most important parameter and is significantly determinated by the number of parts and their volume. Consequently the production time can be reduced by minimizing the process height, for example with an intelligent part orientation or nesting efficiency of the batch. The electrical power for each process is approximately constant, so the electrical consumption depends mainly on the production time and is therefore a function of the production height. The laser unit and the cooling are mainly responsible for the energy consumption of the DTM 2000 and are activated in every stage of the building process. The total energy consumption can be minimized by switching the subsystem on or off over the different phases of the building process whether its needed or not. Another optimizing method can be found in introducing a separate cooling chamber, where the parts can be cooled down, while the machine can be used for the next job. To decrease the consumption another approach can be found by constructing the process chamber more effectively, i.e. with a space saving design and/or better sealing. In addition there is a high amount of waste material. On the one hand the nesting efficiency can be increased to reduce the waste material amount. Within the test runs the waste powder of the building platform get a small percentage of all sales, because the parts were built with densest space. On the other hand the powder coating can be reduced, so less powder gets into the overflow bins. The first experiments show a promising potential for improvement of the lasersintering process regarding the reduction of the process time, the energy consumption and waste material and have to be validated in future projects.

\section{CONCLUSION}

First results of an energetic consideration of the laser-sinter machine DTM 2000 are presented in this paper. After describing the theoretical principle of the laser-sintering process in section 2 , the testing schedule is defined in section 3. The main results are presented in the following sections, including time studies as well as electric power and material studies. Finally, based on this results, possible improvement potentials of the lasersintering machines are shown.

In the longer term the study should be used to find alternative machine components and to examine the reducing of overall energy costs. An extension to other laser-sintering machines will be subject of future research efforts.

\section{REFERENCES}

[1] Wohlers, T. (2011). Wohlers Report 2011: Additive Manufacturing and 3D-Printing, State of the Industry, Annual Worldwide Prozess Report, Wohlers Associates, Colorado, USA

[2] Gebhardt, A. (2007). Generative Fertigungsverfahren. Rapid Prototyping - Rapid Tooling - Rapid Manufacturing, Carl Hanser Verlag, München

[3] Kellens, K. (2010). Enviromental assessment of selektive laser melting ans selective sintering

[4] Franco, A. (2010). Experimental analysis of selective laser sintering of polyamide powders: an energy perspective, Journal of Cleaner Production

[5] VIK Verband der Industriellen Energie- und Kraftwirtschaft e.V. (1/2012): VIK-Kurzmitteilungen

[6] The Association of German Engineers (2009). VDI-Guideline 3404: Additive fabricatin - Rapid technologies (rapid prototyping) Fundamentals, terms and definitions, quality parameters, supply agreements, Beuth Verlag, Berlin

[7] Gibson, I. (2010). Additive Manufacturing Technologies - Rapid Prototyping to direct Digital Manufacturing, Springer Verlag, 978-1-4419-1119-3, New York

[8] Zäh, M. (2007). Wirtschaftliche Fertigung mit Rapid Technologien, Carl Hanser Verlag, München

[9] Lou, Y. (1999). Enviromental performance analysis of solid freedom fabrication prozesses, Proceedings of the 1999 IEEE International Symposium on Electronics and the Enviroment

[10] Mognol, P., Lepicart, D., Perry, N. (2006). Rapid prototyping: energy and enviromental in the spotlight, Rapid Prototyping Journal, Nantes, France

[11] 3D-Systems, www.3dsystems.com 